\title{
Crowned Dens Syndrome Mimicking Meningitis
}

\author{
Kei-ichi Ishikawa, Tsuyoshi Furuya, Kazuyuki Noda and Yasuyuki Okuma
}

Key words: crowned dens syndrome, CT, calcification, meningitis, pseudogout

(Inter Med 49: 2023, 2010)

(DOI: 10.2169/internalmedicine.49.3924)

A

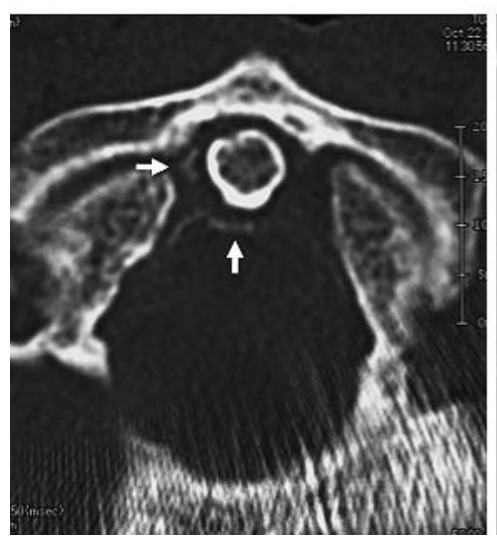

B

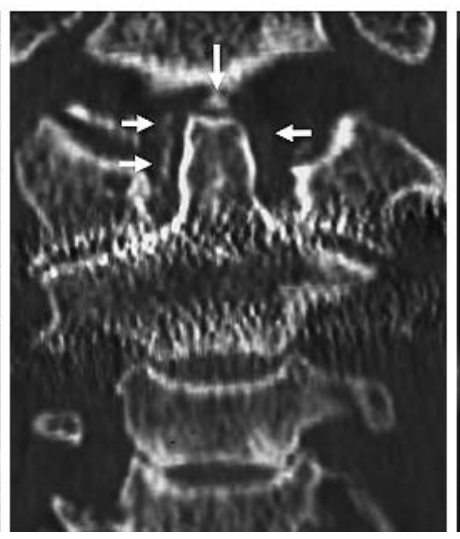

C

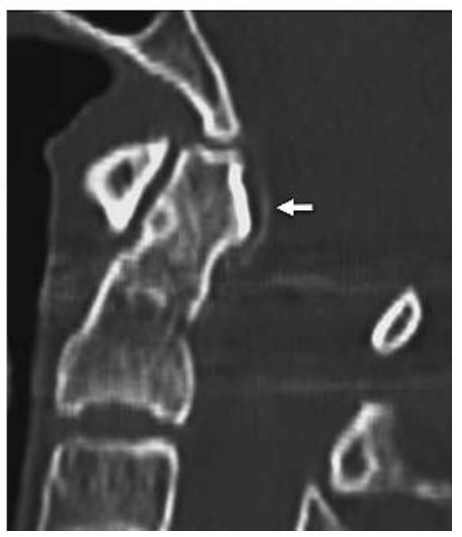

Picture 1.

A 78-year-old woman presenting with fever and occipital headache was referred to our service with suspicion of meningitis. Neurological examination was normal except for cervical stiffness. CRP level was increased to $18.7 \mathrm{mg} / \mathrm{dl}$. Cerebrospinal fluid examination was normal. Cervical CT image at $\mathrm{C} 1 / \mathrm{C} 2$ level showed right dominant semicircular calcifications posterolateral to the odontoid process (dens) (Picture 1A). Coronal view showed crown-like calcifications around the dens (Picture 1B), and sagittal image revealed linear calcification behind the dens (Picture 1C). The diagnosis of crowned dens syndrome (CDS) was made. Her symptoms were completely resolved after NSAID administration.

CDS is characterized by acute neck pain and calcium pyrophosphate dehydrate deposits (pseudogout) around the odontoid process in the elderly $(1,2)$. When encountering a patient with cervical stiffness and inflammatory reactions, it is reasonable to perform lumbar puncture first to rule out meningitis. If the results are negative, CDS should be considered. Anti-septic treatments are not necessary and adequate anti-inflammatory medications including corticosteroids will lead to a successful outcome.

\section{References}

1. Bouvet J-P, le Parc J-M, Michalski B, Benlahrache C, Auquier L. Acute neck pain due to calcifications surrounding the odontoid process: The crowned dens syndrome. Arthritis Rheum 28: 14171420, 1985.

2. Aouba A, Vuillemin-Bodaghi V, Mutschler C, De Bandt M. Crowned dens syndrome misdiagnosed as polymyalgia rheumatica, giant cell arteritis, meningitis or spondylitis: an analysis of eight cases. Rheumatol 43: 1508-1512, 2004.

Department of Neurology, Juntendo University Shizuoka Hospital, Shizuoka

Received for publication May 8, 2010; Accepted for publication June 16, 2010

Correspondence to Dr. Yasuyuki Okuma, sgz02202@nifty.ne.jp

(C) 2010 The Japanese Society of Internal Medicine Journal Website: http://www.naika.or.jp/imindex.html 